\title{
Algal growth inhibition test results of 425 organic chemical substances
}

\author{
Kusk, Kresten Ole; Christensen, Anne Munch; Nyholm, Niels
}

Published in:

Chemosphere

Link to article, DOI:

10.1016/j.chemosphere.2018.04.047

Publication date:

2018

Document Version

Peer reviewed version

Link back to DTU Orbit

Citation (APA):

Kusk, K. O., Christensen, A. M., \& Nyholm, N. (2018). Algal growth inhibition test results of 425 organic chemical substances. Chemosphere, 204, 405-412. https://doi.org/10.1016/j.chemosphere.2018.04.047

\section{General rights}

Copyright and moral rights for the publications made accessible in the public portal are retained by the authors and/or other copyright owners and it is a condition of accessing publications that users recognise and abide by the legal requirements associated with these rights.

- Users may download and print one copy of any publication from the public portal for the purpose of private study or research.

- You may not further distribute the material or use it for any profit-making activity or commercial gain

- You may freely distribute the URL identifying the publication in the public portal

If you believe that this document breaches copyright please contact us providing details, and we will remove access to the work immediately and investigate your claim. 


\section{Accepted Manuscript}

Algal growth inhibition test results of 425 organic chemical substances

Kresten Ole Kusk, Anne Munch Christensen, Niels Nyholm

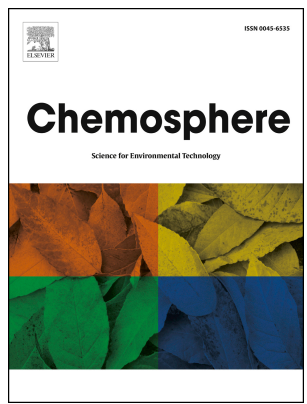

PII: S0045-6535(18)30689-1

DOI: $\quad$ 10.1016/j.chemosphere.2018.04.047

Reference: CHEM 21195

To appear in: $\quad E C S N$

Received Date: 17 January 2018

Revised Date: 6 April 2018

Accepted Date: 9 April 2018

Please cite this article as: Kusk, K.O., Christensen, A.M., Nyholm, N., Algal growth inhibition test results of 425 organic chemical substances, Chemosphere (2018), doi: 10.1016/j.chemosphere.2018.04.047.

This is a PDF file of an unedited manuscript that has been accepted for publication. As a service to our customers we are providing this early version of the manuscript. The manuscript will undergo copyediting, typesetting, and review of the resulting proof before it is published in its final form. Please note that during the production process errors may be discovered which could affect the content, and all legal disclaimers that apply to the journal pertain. 


\section{Algal Growth Inhibition Test Results}

Corresponding author:

15

Kresten Ole Kusk

Department of Environmental Engineering,

Technical University of Denmark

DK-2800 Kgs. Lyngby

21

Denmark

22

e-mail: koku@env.dtu.dk 


\section{Organic Chemical Substances}

${ }^{1}$ Kusk, Kresten Ole, ${ }^{1,2}$ Christensen, Anne Munch, ${ }^{1}$ Nyholm, Niels

30

${ }^{1}$ Department of Environmental Engineering, Technical University of Denmark,

Bygningstorvet 115, DK-2800 Kgs. Lyngby, Denmark 


\section{ABSTRACT}

The toxicity towards the algal species Pseudokirchneriella subcapitata of 425 organic chemical substances was tested in a growth inhibition test. Precautions were taken to prevent loss of the compounds from the water phase and the test system (closed test system, low biomass, shorter test duration, silanized glass) and to keep $\mathrm{pH}$ constant by applying a higher alkalinity. Chemical phase distribution was modelled taking ionization, volatilisation, and adsorption to glass and biomass into consideration. If the modelled water concentration was below $90 \%$ of the nominal concentration the calculated EC values were corrected accordingly. The model helped to identify substances, where the calculated water concentration was too uncertain. Substances covering a wide range of physical-chemical properties and different modes of action were tested. Median effect concentrations $\left(\mathrm{EC}_{50}\right)$ lower than $1000 \mathrm{mg} / \mathrm{L}$ were found for 310 substances; 216 of these were in the range from 1 to $1000 \mathrm{mg} / \mathrm{L}$ and 94 substances had $\mathrm{EC}_{50}$ s below $1 \mathrm{mg} / \mathrm{L}$ and should be classified as "Very toxic". 36 substances fell in the group with $\mathrm{EC}_{50}>1000 \mathrm{mg} / \mathrm{L}$. An $\mathrm{EC}_{50}$ could not be established for 79 substances. These 425 different organic substances were tested under uniform conditions and thus considered a valuable source of information for administrators, industry, risk assessors and QSAR modellers.

\section{Keywords}

Algae, toxicity, chemicals, partioning, QSAR, environmental risk 
The number of chemical substances used in daily life in household, agriculture, industry, etc. is very high. With the EU chemical legislation, covered by e.g. the EU REACH Regulation, CLP Regulation, Biocidal Products Regulation, Pesticide Regulation, all chemical substances unicellular algae.

Environmental hazard and risk assessment and classification of chemical substances as well as the different regulations demand results from ecotoxicological studies, e.g. data from toxicity tests with algae, crustaceans and fish. Ecotoxicological tests are costly and time consuming and this is one reason for the slow and resource-intensive risk assessment process. Alternative methods like QSARs (Quantitative Structure Activity Relationships) are increasingly used in regulatory contexts to supplement experimental data especially for degradation products. QSAR models that can predict/estimate ecotoxicological effects from e.g. structure and physical-chemical properties, therefore provide a valuable tool for performing environmental hazard and risk assessment, PBT (Persistence, Bioaccumulation, Toxicity) assessment and classification much faster and cheaper compared to assessments based on experimental data for each individual compound. QSAR models for predicting ecotoxicological effects on crustacean and fish were some of the first to be developed by the Danish Environmental Protection Agency (2004, 2015.). 
However, for the third important group of organisms, the algae, it was proved difficult to find homogenous data sets to form basis for global (covering a diversity of chemical classes) QSAR models for algae toxicity. Microscopic algae are the most important group of primary producers of biomass in most aquatic ecosystems and thereby form an important ecological base for higher life forms. Toxic effects on this group of organisms may harm the whole ecosystem because the food base of the ecosystem may be harmed leading to secondary effects at higher throphic levels. Thus, it is essential to investigate the effect of toxic substances on this group of organisms.

This paper presents the methods and data generated to develop a model for prediction of ecotoxicity of chemical substances on algae. The final model based on the results presented here and some literature values was run with 170,000 substances in the first version and in a newly updated version with more than 600,000 substances and the outcome is available online (Danish Environmental Protection Agency, 2004, 2015). Only the modelled results are presented in the Danish EPA (Q)SAR database, whereas the experimental results were not published before.

In this project a cost-effective method was used taking special care to achieve precise and reliable results beyond the scope of routine testing. In order to keep the dissolved concentrations of the tested substances as constant as possible, some modifications were done relative to standard test methods (Organization for Economic Cooperation and Development, 1984). Special care was taken to keep the $\mathrm{pH}$ constant, to reduce losses of chemical substance due to sorption on glass and biomass and due to volatilization and degradation and a modified Mackay level 1 partitioning model (Mackay, 1991) for the system taking ionisation into consideration was set up and run for each substance to evaluate the water concentration. 

to generate high quality data under uniform experimental conditions within one laboratory at Technical University of Denmark. The resulting test data set was iteratively used as the basis for development of interim QSAR models throughout the testing period to select new test substances to further strengthen the model and expand its applicability domain. Thus, chemicals covering a broad range of physical-chemical properties and groups were chosen for testing. As 425 different organic chemical substances were tested in exactly the same way we consider these results a valuable source of information for administrators, industry, risk assessors and QSAR modellers.

\section{METHODS AND MATERIALS}

\section{Algae test}

The method used was based on the OECD Guideline 201 (Organization for Economic Cooperation and Development, 1984) and ISO 8692 (International Organization for Standardization, 1997) standards using average growth rate as the endpoint.

The test organism was the green alga Pseudokirchneriella subcapitata, formerly known as Selenastrum capricornutum or as Raphidocelis subcapitata (obtained from the Norwegian Institute of Water Research).

Most chemicals were of analytical grade and at least of 95\% purity. Some modification of the ISO 8692 method was performed to keep the conditions in the test system as stable as possible. A small closed test system was used together with a higher buffer 

modifications will be discussed later.

The stock solutions and test concentrations were prepared with modified ISO 8692 freshwater algal growth media enriched with $200 \mathrm{mg} / \mathrm{L} \mathrm{NaHCO}_{3}$ (4 times higher than ISO medium). The dilution series was prepared by mixing growth media with a stock solution of the test substance and then inoculate with a pre-culture of exponentially growing algal cells propagated under the actual test conditions to eliminate a lag phase. All stock solutions were $\mathrm{pH}$-adjusted to the $\mathrm{pH}$ of the growth media.

Glass vials were used as test vessels. Mini-scale algal growth inhibition tests were conducted as closed tests with $4 \mathrm{~mL}$ test medium and $17 \mathrm{~mL} \mathrm{CO}$-enriched headspace $\left(1 \% \mathrm{CO}_{2}\right)$ as described by Halling-Sørensen et al. (1996). The vials were closed with a teflon-covered septum and $\mathrm{CO}_{2}$ was added with a syringe. At equilibrium with the $\mathrm{CO}_{2}$-enriched headspace the resulting $\mathrm{pH}$ of the media was $7.2 \pm 0.2$. Test vials were incubated on a microplate shaker $(100 \mathrm{rpm})$ in continuous white fluorescent light $\left(70-90 \mu \mathrm{E} \cdot \mathrm{m}^{-2} \cdot \mathrm{s}^{-1}\right)$ at $20 \pm 1{ }^{\circ} \mathrm{C}$.

Algal biomass was determined at the start, after 24 hours and at the end (48 hours) from acetone extractions as described by Mayer et al. (1997). pH was measured at the start and at the end. The fluorescence of the extracted chlorophyll was measured on a Hitachi F-2000 Fluorescence Spectrophotometer with excitation light at $420 \mathrm{~nm}$ and emission light at $671 \mathrm{~nm}$. Algal growth rates in each vial were calculated directly from the fluorescence measurements. Specific average growth rates were calculated for each vial from the three biomass determinations. 

concentration of $1-2 \%$ in the final solution. Results from testing of the solvents are included in the supplementary materials. If a co-solvent was used the concentration was equal in all test concentrations. Potassium dichromate was used as a reference compound and tested every

Each substance was tested in both a range finding test and in a definitive test. The number of replicates in definitive tests varied in the project period. At the start 3 replicates of each of six test concentrations were used. Later, nine test concentrations with two replicates were used. In the last part of the project only one replicate of each of the thirteen concentrations was used as recommended by Andersen et al. (1998). Despite the number of replicate the concentrations were chosen with a constant factor between concentrations (equal distances between concentrations on a logarithmic scale). During the whole period six control replicates were used and run simultaneously to each test substance.

$\mathrm{EC}_{10}$ and $\mathrm{EC}_{50}$ (concentrations reducing the specific average growth rate by 10 and $50 \%$, respectively) and their confidence limits were estimated by fitting the obtained concentrationresponse data to the logarithmic normal distribution function (Christensen et al., 2009). The

\section{Statistical calculations} obtained growth rates were normalised by dividing with the (negative or if a solvent was used the solvent) control response estimate. The influence of the control covariance was taken into account in the statistical calculations using a weighting function that was inversely proportional to the total variance. Further, experimental designs were made with six control 

points for an accurate estimation of the concentration-response relationship.

\section{Phase partitioning}

A partitioning model based on Mackey's fugacity model level 1 (Mackay, 1991), assuming equilibrium was developed. The model estimates the phase distribution of chemical substances between water, algal biomass, air headspace, and glass surface in the test system taking into account ionization, volatilization and sorption to algal biomass and glass. For further details see Christensen et al. (2009). If the estimated water concentration was lower than $90 \%$ of the nominal concentration the test result was corrected accordingly.

Dimensions used for the algal test model were: water $(4.0 \mathrm{~mL})$, air $(17.0 \mathrm{~mL})$, glass wall $(11.3$ $\mathrm{cm}^{2}$ ), and algae (cell density after $48 \mathrm{~h}$ at a growth rate of 1.70$) 3.66 \cdot 10^{5}$ cells $/ \mathrm{mL} \sim$ biomass volume $1.46 \cdot 10^{-4} \mathrm{~mL} .1 \mathrm{mg}$ dwt of algae was equivalent to $5 \cdot 10^{7}$ cells with $10 \%$ carbon content (Christensen, 2009). The carbon content of the final algal biomass was used for estimation of sorption to algae.

For estimation of sorption to glass a study was performed to determine the glass-water distribution coefficient. Sorption was measured in abiotic control experiments using silanized as well as borosilicate (normal) glass and with six different ${ }^{14} \mathrm{C}$-labeled substances to cover the widest possible range of Kow's, see Table 1. Analyses were made using a Tri-Carb 2000 Liquid scintillation Counter (United Technologies Packard). Some experiments were also made with addition of co-solvent (DMSO) in order to investigate if such addition influenced sorption. 

spiked samples were prepared in normal glass vials and six in silanized glass vials. After four, 24 hours and at the end of the experiment (48 hours) samples were taken from three of each glass type and analysed by liquid scintillation counting. Radiolabelled substances adsorbed to the glass were extracted with $4 \mathrm{~mL}$ of acetone under continuous shaking for $24 \mathrm{~h}$ followed by scintillation counting. Isotope mass balances were made and the glass-water partitioning coefficient, $\mathrm{K}_{\mathrm{Glass}}$, was calculated using the equation

$$
\mathrm{K}_{\mathrm{Glass}}=\mathrm{C}_{\mathrm{GLASS}} / \mathrm{C}_{\mathrm{W}} \quad\left(\mathrm{L} / \mathrm{cm}^{2}\right)
$$

where $\mathrm{C}_{\mathrm{GLASS}}$ is the amount of the substance sorbed onto the glass surface $\left(\mathrm{mg} / \mathrm{cm}^{2}\right)$ and $\mathrm{C}_{\mathrm{W}}$ is the water concentration $(\mathrm{mg} / \mathrm{L})$.

For lipophilic compounds, such as phenanthrene and DDT the mass balance indicated that acetone could not extract all of the sorbed substance. In that case $\mathrm{K}_{\text {Glass }}$ was calculated indirectly from the water concentration using nominal concentrations. In the experiment and in the partitioning model it is assumed that sorption to the glass surface only will take place at the glass surface area in contact with the $4 \mathrm{~mL}$ water sample (vial diameter $1.87 \mathrm{~cm}$; surface area $\left.11.3 \mathrm{~cm}^{2}\right)$.

The model assumes quasi-stationary conditions for the partioning processes and takes into account the following two dynamic phenomena: 1) Increasing sorption to the exponentially growing algal biomass, and 2) progression with time of sorption to the glass surface of the test vessel. Both processes result in decreasing water concentration and hence chemical substances sorbed onto the growing algae also become "growth diluted" (decreasing dose per algal dry weight resulting from increased algal dry weight) reducing the toxic impact. 

concentration and hence the toxic impact. The processes are all considered fast due to the small volume and short transport distances (happen within 48 hours). In this way a dynamic problem is turned into a problem of estimating an equilibrium distribution at a specified time (48 hours) and one of solving linear algebraic equations assuming linear partitioning justified by low concentrations.

For the less volatile test substances escape to the air is of little significance, whereas for the more volatile substances equilibrium is assumed to be established within minutes to hours at constant shaking due to the small volumes and short distances. Thus, we assume to have equilibrium between all phases well before the end of the test.

The physical and chemical data that is used in the partioning model was mainly found in or by use of EPISuite (2001-2014) (solubility, molar weight, octanol water partioning coefficient and vapor pressure) and SPARC On-line Calculator (2002-2005) ( $\mathrm{p} K_{\mathrm{a}}$ values). ACD/I-lab (2010-2016) was used to verify data and in some cases to find data when the other data bases failed to come up with values.

\section{Choice of substances}

Chemical substances were chosen based on preliminary QSAR modelling and on molecular

structure (inactive or active fragments e.g. aromatic amino group, aromatic chlorine group, aromatic alcohol group, etc.), mode of action, special physico-chemical properties - including some basic natural structures e.g. amino acids and other organic acids. The choice of test substances was a feedback process based on previous test results and identification of potentially active groups not yet tested. 
All substances were handled and working procedures were performed in accordance to the OECD Guidance Document on Aquatic Toxicity Testing of Difficult Substances and Mixtures (Organization for Economic Cooperation and Development, 2000).

\section{RESULTS AND DISCUSSION}

\section{Partitioning model and sorption to glass}

In this project with more than 400 substances tested it was not possible to verify the concentrations in the tests with chemical analysis. Instead it was chosen to estimate the partitioning of the substances in the four phases of the closed test system, air, algal biomass, glass and water. Due to the small size of the test vessels (short distances) and the continuous shaking it was assumed that equilibrium between the phases was achieved quickly and long before the end of the 48 hours test period.

To use a Mackey's fugacity level I model we needed to find the glass sorption coefficient. In the glass sorption experiments ionization was accounted for. For the six substances used to study glass sorption (Table 1) a mass balance showed that no significant volatilization took place. Furthermore no algae were added in the experiments so sorption to algae could be excluded. In Table 1 physical and chemical properties of the compounds used in these experiments are shown.

The results revealed that sorption to glass surfaces increases with time, but it was almost completed after 24 hours. In the distribution model it was chosen to use data from 48 hours because the duration of the algae test was 48 hours and because equilibrium was complete at that time even for DDT, which had the highest $\mathrm{K}_{\mathrm{ow}}$. 
Addition of DMSO had only little influence on the adsorption and in the distribution model it was chosen not to account for DMSO addition because most tests were performed without a co-solvent.

In Figure 1 correlations between $\mathrm{K}_{\mathrm{Glass}}$ and $\mathrm{Log} \mathrm{K}_{\mathrm{OW}}$ in the range of 0.90 to 6.91 were achieved using polynomial equations; the curves and equations for normal and silanized glass are almost identical:

Normal glass:

$\log \mathrm{K}_{\mathrm{Glass}}=0.0289 \cdot \log \mathrm{K}_{\mathrm{OW}}{ }^{2}+0.1342 \cdot \log \mathrm{K}_{\mathrm{OW}}-2.2986 ; \quad\left(\mathrm{R}^{2}=0.923\right)$

Silanized glass:

$$
\log \mathrm{K}_{\mathrm{Glass}}=0.0307 \cdot \log \mathrm{K}_{\mathrm{OW}}{ }^{2}+0.1065 \cdot \log \mathrm{K}_{\mathrm{OW}}-2.2209 ; \quad\left(\mathrm{R}^{2}=0.903\right)
$$

As could be expected Log Kow alone can describe the sorption. For substances having log $\mathrm{K}_{\mathrm{OW}}$ values lower than zero, it was assumed that no adsorption took place and for these $\mathrm{K}_{\text {Glass }}$ was set to zero. For substances having $\log \mathrm{K}_{\mathrm{OW}}$ values higher than zero the equation for silanized glass was used in the partitioning model

Additionally, investigations of sorption of substances to the glass surface was performed to develop a partitioning model to estimate the partitioning of each test substance in the specific (e.g. Organization for Economic Cooperation and Development, 2008) it is recommended that test results are based on measured concentrations, but if the result of the chemical analysis is within $\pm 20 \%$ of the nominal concentration the test result can be based on nominal 

at or above $90 \%$ of the nominal concentration and it was chosen not to correct these EC values. If the estimated water concentration was between $20 \%$ and $90 \%$ the EC values were corrected accordingly, which was the case in 104 tests. If the model showed a water concentration below $20 \%$, the concentration was considered too uncertain to give trustworthy

\section{Test duration}

Some justified modifications of the standard method ISO 8692 were made to minimise changes in the water concentrations during the test period. One modification was to use a test period of 48 hour instead of the standard period of 72 hours. If the growth is exponential the growth curve in a semi log plot will be a straight line where the slope will correlate the specific growth rate. Thus, as long as the biomass can be measure with a sufficient precision the growth rate of an exponential growing algal culture is independent of time. In our case we were able to measure the biomass precisely enough to get a growth rate based on the three measurements from 0,24 and $48 \mathrm{~h}$, which in the control vials had a correlation coefficient of 0.98 or better in a semi-logarithmic plot.

The average control growth rate in our tests was generally in the range of 1.6-1.9 day ${ }^{-1}$ with a variation coefficient of the control growth rate of less than $3 \%$ and a $\mathrm{pH}$ change of less than \pm 0.2, thus fulfilling the validity criteria of ISO 8692 (International Organization for Standardization, 1997.).

\section{Adsorption and degradation}


Adsorption to the biomass was reduced by using a low inoculate of $10^{4}$ cells/L, by shortening the test duration to 48 hours (from 72 hours normally) and by applying a test temperature in the lower end of the range $\left(21^{\circ} \mathrm{C}\right)$ of that specified by ISO 8692 thereby reducing the final algal biomass. The lower final biomass also helps reducing $\mathrm{pH}$ drift, which mainly takes place at the end of a test where the biomass is highest. Besides, the shorter test duration leaves less

\section{Closed system}

A small, closed system was used with all test substances to avoid volatilisation from the system. pH drift was minimized by increasing the alkalinity in the growth media 4 fold (200 $\mathrm{mg} \mathrm{NaHCO} / \mathrm{L})$ relative to the ISO standard and by injecting $\mathrm{CO}_{2}$ to the headspace $\left(1 \% \mathrm{CO}_{2}\right)$ resulting in a $\mathrm{pH}$ of the medium of $7.2 \pm 0.2$. This also optimizes the $\mathrm{CO}_{2}$ supply of the alga. $\mathrm{pH}$ may increase in standard algal tests due to uptake of $\mathrm{CO}_{2}$ by the alga, which for ionizing compounds means that the fraction of the (toxic) non-ionized species will change during the test. By adding more bicarbonate and carbon dioxide to the system such a $\mathrm{pH}$ change was minimized, and thereby the fraction of the non-ionized substance becomes more constant and 

(2006) and by Fu et al. (2015). Fu et al. evaluated algal toxicity data from many different sources and found indications that 48 hours tests were slightly more sensitive than 72 hours tests; besides they found that tests performed in open and closed systems had the same sensitivity for most test compounds. Aruoja et al. $(2011,2014)$ tested 50 nonpolar and 58 polar narcotics and obtained results in a closed and open test that were sufficiently similar for a direct comparison. In contrast to Tsai and Chen (2007) tested 90 organic compounds and found 2 to 380-fold higher sensitivity ( lower EC values) in closed tests. Pseudokirchneriella subcapitata (formerly Selenastrum capricornutum or Raphidocelis subcapitata) were used in all these cited papers.

\section{Tests with reference compound}

In Table 2 is shown the result of tests performed with potassium dichromate $\left(\mathrm{K}_{2} \mathrm{Cr}_{2} \mathrm{O}_{7}\right)$ during the project period. An average $\mathrm{EC}_{50}$ of $0.60 \mathrm{mg} / \mathrm{L} \mathrm{K}_{2} \mathrm{Cr}_{2} \mathrm{O}_{7}$ was found in 14 tests with a standard deviation of $0.16 \mathrm{mg} / \mathrm{L}$ and a coefficient of variation of $25 \%$. Thus, the sensitivity of the test was constant during the project period. The average $\mathrm{EC}_{50}$ is lower than results presented by ISO from an inter-laboratory investigation, where an average $\mathrm{EC}_{50}$ of $1.19 \mathrm{mg} / \mathrm{L}$ was found (International Organization for Standardization, 1997), but this is probably caused by the lower $\mathrm{pH}$ used here ( $\mathrm{pH} 7.2 \pm 0.2$ versus $8.1 \pm 0.2$ in standard ISO tests).

\section{Chemical substances}

In total 425 organic chemical substances including three co-solvents (DMSO, acetone and chloroform) were tested. None of the co-solvents had any effect on the growth at the concentrations at which they were added as co-solvents. Besides solvents at low concentrations do not significantly influence the water solubility in accordance with basic physical/chemical principles (ECETOC, 1996) and, thus, will not change the partioning of the 
test substances. The test substances belong to different groups: narcotic, non-narcotic, polar, non-polar, specific reacting and non-specific reacting substances, but were not characterized as such before testing because the preliminary test result gave the concentration range to be tested in the definitive test. In Figure 2A is shown a distribution of $\log \mathrm{K}_{\mathrm{ow}}$ values for the

For a series of substances it was not possible to find $\mathrm{p} K_{\mathrm{a}}$ values. Among these are the quaternary ammonium compounds, which are permanently charged. To evaluate their partioning we assumed a worst case scenario where they we considered them uncharged when we estimated their partitioning. In most cases the model predicted more than $90 \%$ of the (uncharged) substance to be found in the water phase, which means that the charged water fraction was probably higher. These substances had relatively low $\mathrm{K}_{\mathrm{ow}}$ 's and high water solubility, so one would expect most of the compounds in the water phase. Though, for two compounds, 1-Heptanaminium, N,N,N-triheptyl-, bromide (CAS 4368-51-8) and 1Octanaminium, N-methyl-N,N-dioctyl-, chloride (CAS 5137-55-3) the percentages of the uncharged fraction in water were estimated to $1.5 \%$ and $24 \%$, respectively. Since they are charged, these two compounds will probably not behave like neutral compounds. Thus, it is not possible to estimate their water phase concentration with any certainty and therefore the EC values for these two substances are neither shown in the distribution of $\mathrm{EC}_{50}$ values 
(Figure 2D) nor under the corrected EC values (but can still be seen under the uncorrected values in the Supplemental materials Table 1).

Another problematic group is the polyfluorinated substances of which we tested about 20. When assuming these substances were uncharged, the distribution model showed that for most of these more than $70 \%$ was in the water phase. Though, for four of them the model showed that $1 \%$ or less was in the water phase. These were Butane, $1,1,1,2,2,3,3,4,4-$ nonafluoro-4-iodo- (CAS 423-39-2); 1-Octanol, 3,3,4,4,5,5,6,6,7,7,8,8,8-tridecafluoro- (CAS 647-42-7); Furan, 2,2,3,3,4,4,5-heptafluorotetrahydro-5-(nonafluorobutyl)- (CAS 335-36-5);

Figure 2B shows the distribution of molar weights of the 425 test chemical substances. More than $80 \%$ of the substances had molar weight in the range from 100 to 300.35 had molar weights above 350.

Henry's law constants (Log values) are shown in Figure $2 \mathrm{C}$. Substances with $\log \mathrm{K}_{\mathrm{H}}$ values lower than $-6.5 \mathrm{~atm} \cdot \mathrm{m}^{3} \cdot \mathrm{mol}^{-1}$ are less volatile than water and are not expected to escape to the air phase (Lyman, 1990). Compounds with a log $\mathrm{K}_{\mathrm{H}}$ above $-3 \mathrm{~atm} \cdot \mathrm{m}^{3} \cdot \mathrm{mol}^{-1}$ can be considered as volatile. 43 of the tested compounds belong to this group, which justifies the use of a closed test system. 
$\mathrm{EC}_{50}$ values were determined for 346 substances (Figure 2D). $\mathrm{EC}_{50} \mathrm{~s}$ lower than $1000 \mathrm{mg} / \mathrm{L}$ were found for 310; 216 of these can be classified as "Toxic" ( $\mathrm{EC}_{50}$ from 1 to $\left.1000 \mathrm{mg} / \mathrm{L}\right)$ (depending of their toxicity to other groups of organisms their classification might be stricter) (Van Leeuwen and Hermens, 1995). 94 substances had $\mathrm{EC}_{50} \mathrm{~s}$ below $1 \mathrm{mg} / \mathrm{L}$ and shall be estimation of the water phase concentration was too uncertain.

\section{Partitioning examples}

Some results from the partitioning model are show in Figure 3. N-(butoxymethyl)-2-chloroN-(2,6-diethylphenyl)acetamide (CAS 23184-66-9) (Fig. 3A) is a neutral compound with a $\log \mathrm{K}_{\mathrm{ow}}$ of 4.84 and $72 \%$ is found in the water phase, $21 \%$ on the glass and $7 \%$ on the algae. In cases like this the obtained EC values were corrected since the predicted water concentration was significantly below $(<90 \%)$ the nominal concentration.

In Figure 3B is estimated the partitioning of 2,4,6-Tri-tert-butylaniline (CAS 961-38-6). It has a $\log \mathrm{K}_{\mathrm{Ow}}$ of 6.8 and a low water solubility of $0.3 \mathrm{mg} / \mathrm{L}$. As expected most of the material is sorbed, $73 \%$ to the biomass and $18 \%$ to the glass leaving only $8 \%$ in the water phase. In cases like this we have generally considered the partioning model results too uncertain. In the case 
Figure $3 \mathrm{C}$ shows the estimated partitioning between air, algal biomass, glass and water of pamino benzoic acid methyl ester (CAS 619-45-4). This compound has a low Log $\mathrm{K}_{\mathrm{OW}}$ of 1.37. Almost all the substance is dissolved in the water phase and only $3 \%$ is expected to sorb to the glass of the test vial. The compound is a base with a $\mathrm{p} K_{\mathrm{a}}$ of 2.37 and is not expected to ionize at the test $\mathrm{pH}$. The majority of chemicals tested behaved like this one either because they had a low $\mathrm{K}_{\mathrm{ow}}$ and relatively high water solubility or because they ionized at the test $\mathrm{pH}$ leaving most of the compound in the water phase.

Figure 3D shows the partitioning of the neutral and highly volatile compound 1-methylcyclohexene (CAS 591-49-1) with a $\log \mathrm{K}_{\mathrm{H}}$ of $-1.16 \mathrm{~atm} \cdot \mathrm{m}^{3} \cdot \mathrm{mol}^{-1} \cdot 91 \%$ of the compound was expected to be found in the air volume of the closed system and only $7 \%$ in the water. Adsorption to the glass is low - only $1 \%$ due to a relative low fraction of the compound in the water and a moderate $\log \mathrm{K}_{\mathrm{ow}}$ of 3.51 . With only $7 \%$ in the water phase some uncertainty accompanies this result. Thus, correction of EC values have not been done, but the uncorrected

\section{CONCLUSION}

In this work the toxicity towards the single cellular algal species Pseudokirchneriella subcapitata of 425 organic compounds was investigated in a growth inhibition test performed in a closed system. Chemical substances covered a wide molecular weight range, wide $\mathrm{K}_{\mathrm{OW}}$ (and solubility) range, and a wide volatility range, and in the end it showed a wide toxicity range. Precautions were taken to prevent loss of the substances from the water phase and the test system (closed test system, low biomass, shorter test duration, silanized glass) and to keep $\mathrm{pH}$ constant. Phase distribution was modelled taking ionization, adsorption to glass and biomass, and volatilisation into consideration. If the modelled water concentration was below $90 \%$ of the nominal concentration the calculated EC values were corrected accordingly. If the modelled water concentration was below $20 \%$ of the nominal concentration the calculated EC values were considered too uncertain and no corrected EC values were given. Then only 
the uncorrected EC values were given in the supplemental material. $\mathrm{EC}_{50}$ lower than $1000 \mathrm{mg} / \mathrm{L}$ was found for 310 substances; 216 of these were in the range from 1 to $1000 \mathrm{mg} / \mathrm{L} .94$ substances had an $\mathrm{EC}_{50}$ below $1 \mathrm{mg} / \mathrm{L}$ and should be classified as "Very toxic" according to the EU classification. 36 substances fell in the group with $\mathrm{EC}_{50}>1000 \mathrm{mg} / \mathrm{L}$. An $\mathrm{EC}_{50}$ was not found for 79 chemicals. Chemicals from many different groups and with different physical-chemical properties and active molecular fractions, thus with different modes of action, were tested. As 425 different organic chemicals were tested in exactly the same way we consider these results a valuable source of information for environmental administrators, industry using existing or developing new substances or products, environmental risk assessors, QSAR modellers and others working with environmental risk assessing.

\section{Supplemental material}

All data and results from testing of 425 organic chemical substances (plus the reference compound potassium dichromate [CAS 7778-50-10]) are listed in the Supplemental material Table 1.

The Table 1 includes:

- CAS number

- Name

- $\mathrm{EC}_{10}$ and $\mathrm{EC}_{50}$ and their $95 \%$ confidence limits (corrected accordingly if less than $90 \%$ in water phase)

- Physical and chemical properties (Log $\mathrm{K}_{\mathrm{Ow}}$, water solubility, molar weight, vapour pressure, acid dissociation constant)

- Base or acid characteristic of substance

- Dissolved fraction of the substance present in the water phase (ionized plus dissolved estimated using the partitioning model)

- Unionized fraction of the substance 
- If a solvent was used, the amount (in \%) and the kind of solvent is given

- Other remarks (if any)

- Uncorrected $\mathrm{EC}_{10}$ and $\mathrm{EC}_{50}$ and their $95 \%$ confidence limits (nominal concentrations)

For some substances a 50\% inhibition of the growth rate was not reached at the water solubility limit. If the extrapolated $\mathrm{EC}_{50}$ was less than two times the highest test concentration, the $\mathrm{EC}_{50}$ was included. Values higher than this were considered too uncertain and the result was given as "higher than" the highest test concentration.

\section{AKNOWLEDGEMENT}

The project was supported by the Danish Environmental Protection Agency under the following contract No.: J.nr. M 7041-0206; J.nr. M 7041-0334; J.nr. M 7041-0349; J.nr. M

A group of highly skilled laboratory technicians at DTU Environment are thanked for their excellent and precise work: Jane Bergstrøm, Signe Qualmann, Susanne Kruse, and Birthe 
ACD/I-Lab 2.0. 2010-2015. ACD Labs. Available on: https://ilab.acdlabs.com/iLab2/

Andersen, J.S., Holst, H., Spliid, H., Baun, A., Nyholm, N. 1998. Continuous ecotoxicological data evaluated relative to a control response. J Agric Biol Environ Stat 3: 405-420. anilines and phenols to algae Pseudokirchneriella subcapitata and bacteria Vibrio fischeri: Comparison with published data and QSARs. Chemosphere 84: 1310-1320.

Aruoja, V., Moosus, M., Kahru, A., Sihtmäe, M., Maran, U. 2014. Measurement of baseline toxicity and QSAR analysis of 50 non-polar and 58 polar narcotic chemicals for the alga Pseudokirchneriella subcapitata. Chemosphere 96: 23-32.

Christensen, E.R., Kusk, K.O., Nyholm, N. 2009. Dose-response regressions for algal growth and similar continuous endpoints: Calculation of $\mathrm{EC}_{10}$ based on $\mathrm{EC}_{50}$ and slope at $50 \%$ inhibition. Environ Toxicol Chem 28 (4): 826-835.

Danish Environmental Protection Agency. 2004, 2015. Danish (Q)SAR Database available online at: http://qsar.food.dtu.dk

ECETOC 1996. Aquatic toxicity testing of sparingly soluble, volatile and unstable substances.

E Van Nieuwenhuyse 4 (Bte 6), B-1160 Brussels, Belgium. 
Fu, L., Li, J.J., Wang, Y.W., Wang, X.H., Qin, W.C., Su, L.M., Zhao, Y.H. 2015. Evaluation of toxicity data to green algae and relationship with hydrophobicity. Chemosphere 120: 1622.

Halling-Sørensen, B., Nyholm, N., Baun, A. 1996. Algal toxicity tests with volatile and hazardous compounds in air-tight tests flasks with $\mathrm{CO} 2$ enriched headspace. Chemosphere 32:1513-1526.

Hsieh, S.H., Hsu, C.-H., Tsai, D.Y., Chen, C.-Y. 2006, Qunatitative structure-activity relationships for toxicity of nonpolar narcotic chemicals to Pseudokirchneriella subcapitata. Environ Toxicol Chem 25: 2920-2926.

International Organization for Standardization. 1997. Water quality - Fresh water algal growth test with Scenedesmus subspicatus and Raphidocelis subcapitata. ISO Standard 8692, Geneva, Switzerland.

Lin, J.-H., Kao, W.-C., Tsai, K.-P., Chen, C.-Y. 2005. A novel algal toxicity testing technique for assessing the toxicity of both metallic and organic toxicants. Water Res 39: $1869-1877$.

Lyman, W.J., Reel, W.F., Rosenblatt, D.H. 1990. Handbook of chemical property estimation methods. Environmental behavior of organic compounds. American Chemical Society, Washington DC USA. Pp. 15.1-15.34. 
Mayer, P., Cuhel, R., Nyholm, N. 1997. A simple in vitro fluorescence method for biomass measurements in algal growth inhibition tests. Water Res 31: 2525-2531.

Mayer, P., Nyholm, N., Verbruggen, E.M.J., Hermens, J.L.M., Tolls, J. 2000. Algal growth inhibition test in filled, closed bottles for volatile and sorptive materials. Environ Toxicol

Chem 19: 2551-2556

Organization for Economic Cooperation and Development. 1984. OECD 201. Guideline for 602

Organization for Economic Cooperation and Development. 2000. Guidance Document on Aquatic Toxicity testing of Difficult Substances and Mixtures. OECD Series on testing and

Organization for Economic Cooperation and Development. 2008. OECD 211. "Daphnia magna Reproduction Test”. OECD, Paris, France.

609 Assessment No 23. OECD, Paris, France. 
https://archemcalc.com/sparc/.

618

US Environmental Protection Agency 2001-20014. EPISuite ver. 3.10 and 3.11. Available on:

$620 \quad$ http://www.epa.gov/oppt/exposure/docs/episuitedl.htm

621

Van Leeuwen, C.J., Hermens, J.L.M. 1995. Risk Assessment of Chemicals: An Introduction. Kluwer Academic Publishers, Dordrecht.

624 
Figure legends:

Figure 1: Sorption of six chemical substances to normal and silanized glass after 48 hours

Figure 2: Distribution of the test substances with respect to

A: Log $\mathrm{K}_{\text {ow }}$ (octanol-water partitioning constant)

B: Molecular weight

C: Log $\mathrm{K}_{\mathrm{H}}$ (Henry's constant)

$\mathrm{D}$ : $\mathrm{EC}_{50}$ values (corrected)

Figure 3: Estimated partitioning of four test substances:

A: N-(butoxymethyl)-2-chloro- $\mathrm{N}$-(2,6-diethylphenyl)acetamide (CAS 23184-66-9)

B: 2,4,6-Tri-tert-butylaniline (CAS 961-38-6)

C: $p$-amino benzoic acid methyl ester (CAS 619-45-4)

D: 1-methyl-cyclohexene (CAS 591-49-1)

Figure 4: Correlation between $\mathrm{EC}_{50}$ s obtained by Aruoja et al. $[23,24]$ and by DTU. The solid line represents the 1:1 ratio. 
Table 1: Physical and chemical properties of the compounds used in the sorption experiment. Data from US EPA EPISuite (2001-2014) and ACD (2010-2015).

\begin{tabular}{|c|c|c|c|c|c|c|}
\hline CAS & NAME & Log $K_{\text {ow }}$ & *Sol (mg/L) & ${ }^{* *} \mathrm{MOLW}$. & $* * * \mathrm{VAP}(\mathrm{mm} \mathrm{Hg})$ & $\mathrm{p} K_{\mathrm{a}}$ \\
\hline $50-29-3$ & DDT $\not x$ & 6.91 & $5.50 \cdot 10^{-3}$ & 354.49 & $7.5 \cdot 10^{-6}$ & - \\
\hline $57-63-6$ & Ethenyl estradiol \# & 3.67 & $1.13 \cdot 10^{2}$ & 296.41 & $1.95 \cdot 10^{-9}$ & 10.2 \\
\hline 62-53-3 & Aniline \% & 0.90 & $2.08 \cdot 10^{4}$ & 93.13 & $7.91 \cdot 10^{-1}$ & 4.6 \\
\hline $85-01-8$ & Phenanthrene $\not$ & 4.46 & $6.77 \cdot 10^{-1}$ & 178.24 & $4.32 \cdot 10^{-5}$ & - \\
\hline $100-02-7$ & 4-Nitrophenol \# & 1.91 & $7.51 \cdot 10^{3}$ & 139.11 & $2.90 \cdot 10^{-3}$ & 7.1 \\
\hline $106-47-8$ & 4-Chloroaniline \% & 1.83 & $3.90 \cdot 10^{3}$ & 127.57 & $2.70 \cdot 10^{-2}$ & 4.0 \\
\hline \multicolumn{2}{|c|}{$\begin{array}{l}{ }^{*}: \text { Solubility in water } \\
*_{* *}: \text { Molecular weight } \\
* * *: \text { Vapor pressure }\end{array}$} & $\begin{array}{l}\text { q: Neutra } \\
\text { \#: Acid } \\
\%: \text { Base }\end{array}$ & pound & & & \\
\hline
\end{tabular}

Table 2: $\quad$ Results of closed tests with reference compound potassium dichromate at pH 7.2.

$\mathrm{N}$ (Number of tests with reference compound): $\quad 14$

$\mathrm{EC}_{50}$ mean value: $\quad 0.60 \mathrm{mg} / \mathrm{L}$

Standard deviation: $\quad 0.16 \mathrm{mg} / \mathrm{L}$

Coefficient of variation: $\quad 25 \%$ 


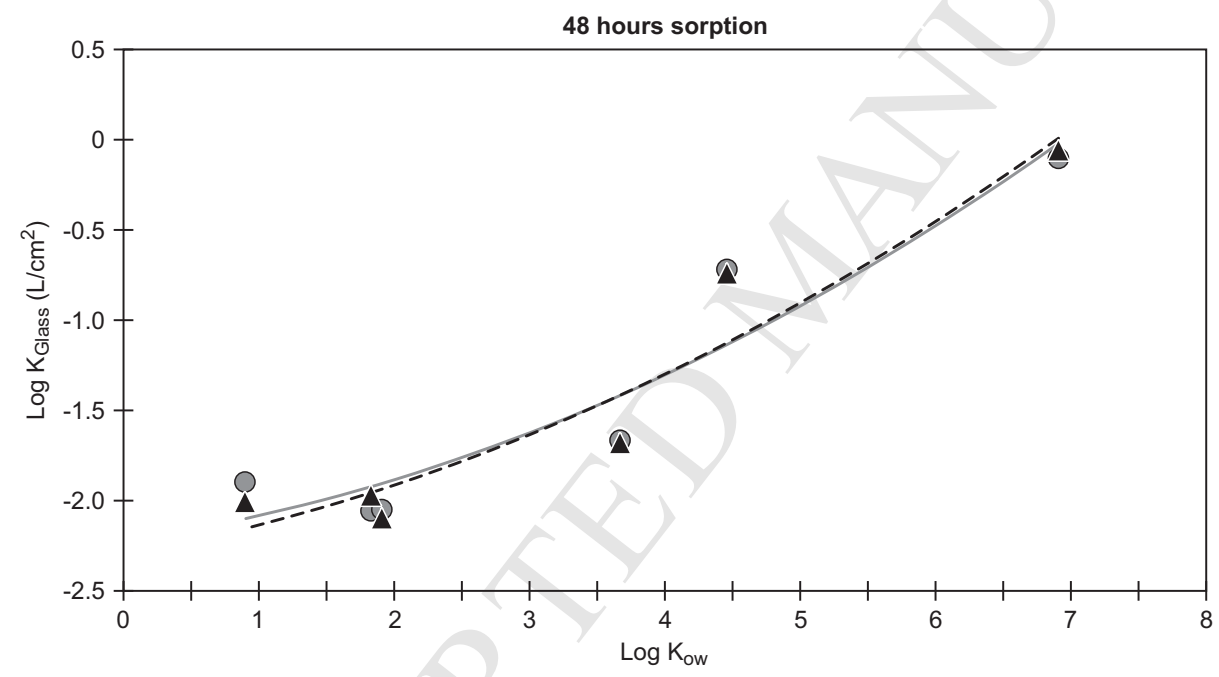

Normal glass: $--\Delta--y=0.0289 x^{2}+0.1342 x-2.2986$ Silanized glass: $-\mathrm{y}=0.0307 \mathrm{x}^{2}+0.1065 \mathrm{x}-2.2209$ 

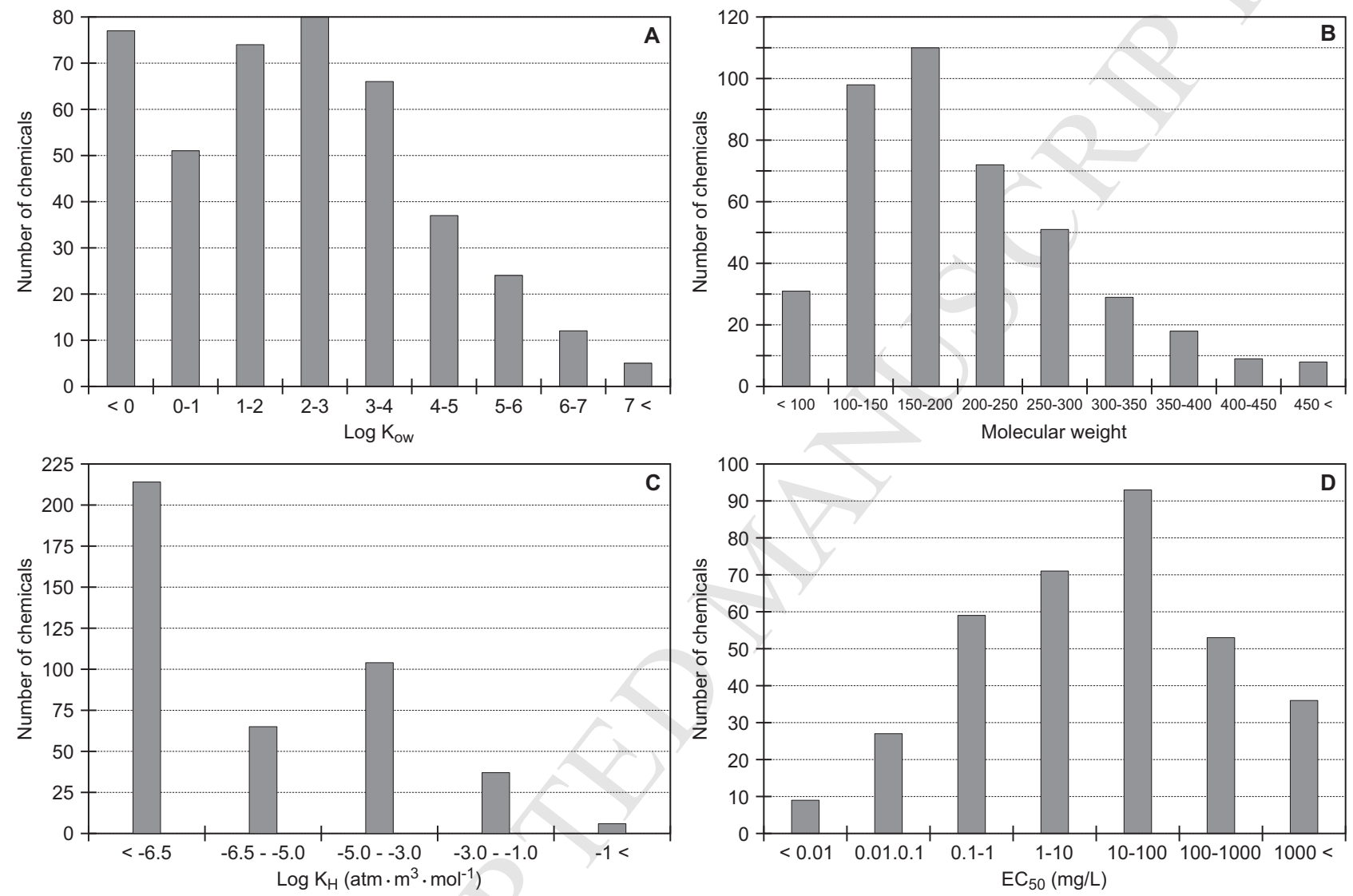


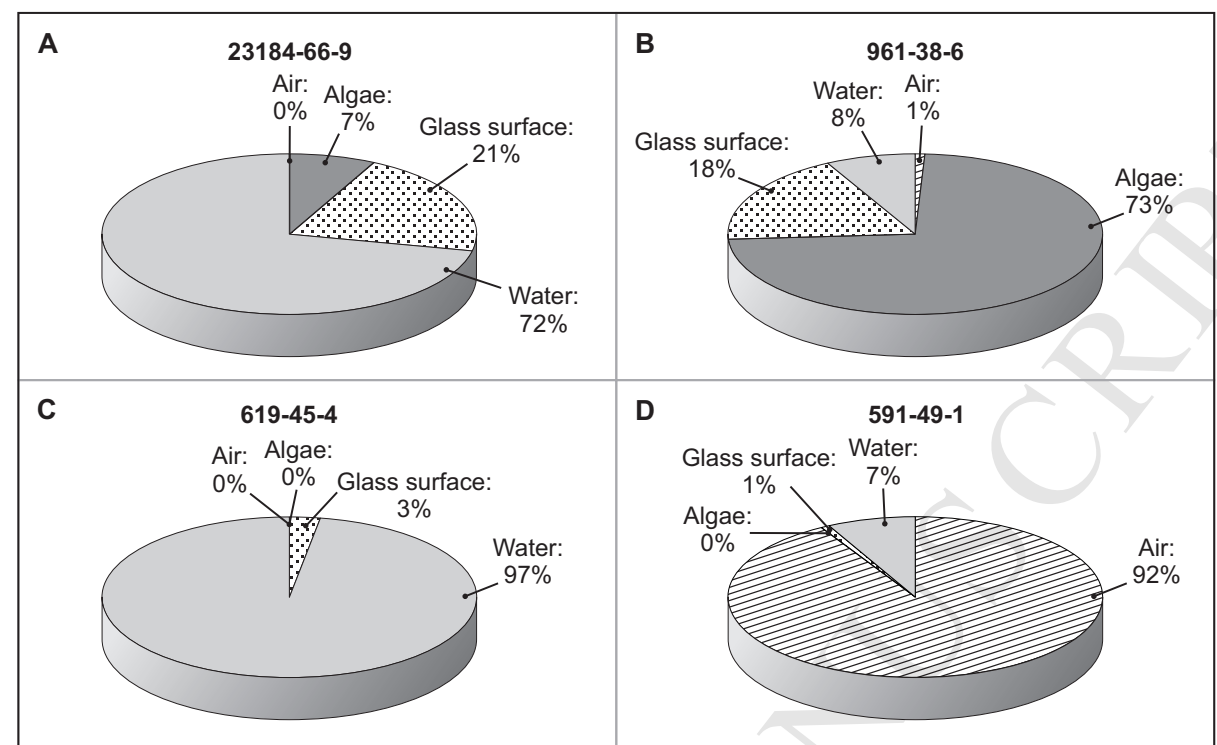

$\square$ Air $\square$ Algae $\quad \square$ Glass surface $\square$ Water 


\section{Highlights}

- More than 400 algal tests were performed under identical conditions

- Chemical phase distribution was modelled using Mackay level I

- The model helped to identify substances with low and uncertain concentrations

- $\mathrm{EC}_{50}$ for 94 substances were below $1 \mathrm{mg} / \mathrm{L}$ and should be classified as "Very toxic"

- Results are considered important for environmental risk assessment 